\title{
The Effects of Paternal Support and Maternal Support on Vocational Exploration and Commitment of Taiwanese College Students
}

\author{
Ching-Hua Mao
}

\begin{abstract}
In this study, the effects of paternal support and maternal support on the Vocational Exploration and commitment to career choices of 368 Taiwanese college students were examined. Based on an integrative literature review, this study designed four constructs pertaining to paternal/maternal support: emotional support, information provision, esteem and autonomy support, and tangible assistance. The Commitment to Career Choices Scale (CCCS) was divided to two dimensions: a Vocational exploration and Commitment (VEC) dimension reflecting variations in one's level of commitment to career choices, and a Tendency to Foreclose (TTF) dimension assessing individual differences in how one commits to career choices. According to the results of regression analysis, the esteem and autonomy support from mothers negatively predicted vocational exploration and commitment (VEC). Furthermore, the esteem and autonomy support from fathers was the only negative and significant predictor of the tendency to foreclose. The negative relationship represents openness to the exploratory experiences of the commitment process with paternal support. The other three significant predictors, esteem and autonomy support from mothers, information support from mothers, and emotional support from fathers, were positively correlated with the tendency to foreclose.
\end{abstract}

Index Terms-Vocational exploration and commitment, paternal support, maternal support, tendency to foreclose.

\section{INTRODUCTION}

Vocational exploration and commitment (VEC) are issues that have attracted substantial interest recently. Because of the increasing unemployment rates of younger generations both in Taiwan and worldwide, younger generations must explore and understand their personalities, abilities, interests, and needs to prepare themselves and establish goals for the challenges that occur in depressed economic environments.

\section{LITERATURE REVIEW}

\section{A. Relational Approach to Career Development}

The relational approach to career development has been of emerging interest in recent years. This approach focuses on the connection between a person's quality of interactional relationships and career development. The relational approach to career development also assumes that significant others are a resource that seriously affects the process of career exploration and career decision-making [1],

Manuscript received September 5, 2013; revised November 19, 2013.

Ching-Hua Mao is with the Chihlee Institute of Technology, Taiwan (e-mail: chcmao@mail.chihlee.edu.tw).
[2]. Furthermore, postmodern social constructionism emphasizes the influence of contextual factors on the individual, which greatly affects the relational approach to career development [3], and combines the structure of context with career development. Research confirms that parental support is the most important interactive context element that influences career development [4], [5].

Chinese society is a collectivist society that values relationships with other people; therefore, the study of support relationships and career development is valuable [1], [2]. Research by Tang, Fouad, and Smith [6], on predictive factors that influence Asian-American university students when making career decisions found that the family involvement variable within immigrant families directly affects career choices. The personal interests of these Asian-American university students had no significant correlation with their career choices, whereas other American university students' interests were directly correlated with their career choices [7]. The difference between Western families and Chinese families regarding the effect of parental roles on children's career choices prompts investigation.

\section{B. Super's Model of Career Development and Marcia's Identity Theory}

Vocational commitment is critical for college students. From the perspective of Super's model of career development, the exploration stage for college students involve selecting suitable jobs by combining their self-exploratory and career-exploration concepts regarding learning, recreational activities, and various work experiences with their interests, abilities, personalities, and needs [8]. At this stage, college students begin to transform their career and vocation dreams into reality, the stage of which represents vocational commitment.

Based on the youth-identity development discussed by Erik Erikson, Marcia proposed two identity-formation dimensions: exploration and commitment, which were subsequently used to divide identity into four stages. a) Achievement: This involves exploration and commitment. Students have established goals, formulated plans to achieve their goals, and made commitments for the future. b) Foreclosure: Students who lack exploratory experience typically accede to family expectations (or significant others) and make future commitments directly without considering other options. c) Diffusion: Students lack exploration and commitment; they possess no thoughts regarding their goals and future and live in the present rather than considering educations or job opportunities. d) Moratorium: Students who are exploring their goals and thus have yet to reach a conclusion; they are confronted with an identity crisis as 
proposed by Erikson, but they will seek answers regarding future commitments.

Marcia's identity formation model indicates that exploration and commitment are needed to develop achievement identity. During this process, parents should provide their children with autonomy support, thereby allowing them to explore without having to comply with family expectations. Alternatively, parents could provide emotional support by encouraging and caring for their children to assist them with managing their confusion and anxiety during this process. Therefore, college students who receive autonomy and emotional support can overcome identity crises through exploration and commit to vocational decisions.

\section{Parental Support and Related Studies}

Many qualitative studies have explored this field of study. Schultheiss et al. [9], conducted personal interviews to understand the roles of relationships between respondents and their parents, siblings, and other important people during the process of respondent career development, and the correlation of these relationships with career exploration and decisions. Schultheiss et al. concluded that relationships are a multi-dimensional source of support; the dimensions of support include emotional support, social integration (that is, network support), esteem support, information support, and tangible assistance, role in difficult career decisions, role model influences, and emphasized financial aspects of choices.

Blustein et al. [10], qualitatively analyzed the intersection of work and inter-personal relationships and identified relationship-related topics from published research cases. They indicated that relationship support is a distinct category which includes emotional and tangible assistance. Tangible assistance is further divided into information and financial support. The participants in a study by Phillips, Christopher-Sisk, and Gravino, as in [11], were workers who had entered the workplace after graduating from high-school. The types of relationships that influenced their career decision-making included emotional and information support (the terminology used in the study was unconditional support, information provided, and alternatives provided).

All of the studies described agree that relationship support is multi-dimensional, but in these studies, parents were not the focus of support-providers and study respondents all had Western backgrounds. Therefore, the effects of paternal support and maternal support on the commitment to career choices in Chinese cultural context where relationships and family connections are highly valued are worth investigating.

In conclusion, the trend in career research is to attempt to understand the effect of contextual factors on career development. The purpose of this study was to find the answers to the following research questions: a) Is paternal support a significant predictor of vocational exploration and commitment of Taiwanese college students? b) Is maternal support a significant predictor of vocational exploration and commitment of Taiwanese college students? c) Which is the main indicator in predicting vocational exploration and commitment maternal support or paternal support?

\section{METHOD}

\section{A. Participants}

The respondents were 368 students from 8 colleges located in northern and eastern Taiwan; $42.3 \%$ were male and $57.7 \%$ were female. The average age was 20.48 (SD = 1.532).

\section{B. Measures}

The instruments contain four parts: a) a demographic questionnaire, b) the Maternal Support Scale, c) the Paternal Support Scale, and d) the Vocational Exploration and Commitment Scale which are detailed below:

\section{1) Marental support and paternal support scale}

The Parental Support Scale measures the degree of maternal and paternal support in youth career development. Based on the theoretical frameworks of Cutrona [12] and the qualitative research findings of Schultheiss et al. [9], Blustein et al. [10], Schultheiss et al. [13], and Phillips et al. [11], this study designed 34 items under four factors, which are a) Emotional Support (e.g., care, support, and encouragement), b) Esteem and Autonomy Support (e.g., parents believe in their offsprings' abilities and respect their choices), c) Information Provision (e.g., providing information on career choices, and giving directions and suggestions), and d) Tangible Assistance (e.g., parental involvement and assistance). Based on a sample of 368 students, the internal reliability coefficient for the 34 items was .913. The Cronbach's alpha values were .90, .83, .83, and .74 for Emotional Support, Esteem and Autonomy Support, Information Provision, and Tangible Assistance, respectively. In order to test for consistency between the scales and the theoretical frameworks, the study conducted confirmatory factor analysis and found: $\chi 2(84)=277.63$, $\mathrm{RMSEA}=0.074, \mathrm{SRMR}=0.05, \mathrm{GFI}=0.92$, and $\mathrm{CFI}=0.98$, suggesting that the model fits well with the theory and that the scale is applicable.

\section{2) Commitment to career choices scale}

The Commitment to Career Choices Scale (CCCS) developed by Blustein, Ellis, and Devenis [14] was divided to two dimensions: a Vocational exploration and Commitment (VEC) dimension reflecting variations in one's level of commitment to career choices, and a Tendency to Foreclose (TTF) dimension assessing individual differences in how one commits to career choices. The VEC consists of 19 items that assesses progress in the commitment process from an uncommitted, exploratory phase to a highly committed phase. The individuals of higher score of VEC would very likely commit to a particular career choice, aware of obstacles, and overcome those obstacles. The TTF consists of 9 items that assesses a continuum that ranges from openness to the experiences of the commitment process to a closed, dualistic approach. The individuals of higher score of TTF would very likely adhere to the belief that only one specific career goal right for them. Cronbach's alpha coefficients were computed in both the derivation and cross-validation samples, yielding acceptable as of .82 and .78 for the TTF and .92 and .91 for the VEC, respectively. 


\section{RESULTS}

The regression results in Table I show that paternal emotional support, esteem and autonomy support, information provision, and tangible assistance failed to significantly predict children's VEC. Concerning maternal support, only esteem and autonomy support predicted children's VEC significantly, and the predictive relationship was negative, indicating that when mothers endow their children with esteem and autonomy support, these children tend to lack VEC.

TABLE I: RESULTS FROM THE REGRESSION ANALYSIS THAT PREDICTS VOCATIONAL EXPLORATION AND COMMITMENT FROM MATERNAL

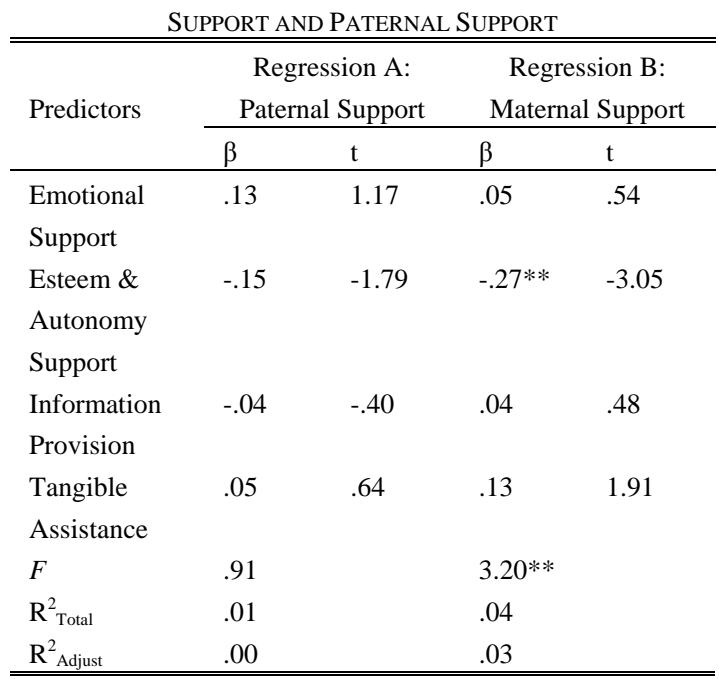

Note. $* p<.05 * * p<.01 * * * p<.001$

TABLE II: RESULTS FROM THE REGRESSION ANALYSIS THAT PREDICTS TENDENCY TO FORECLOSE FROM MATERNAL SUPPORT AND PATERNAL SUPPORT

\begin{tabular}{|c|c|c|c|c|}
\hline \multirow[t]{2}{*}{ Predictors } & \multicolumn{2}{|c|}{$\begin{array}{c}\text { Regression A: } \\
\text { Paternal Support }\end{array}$} & \multicolumn{2}{|c|}{$\begin{array}{c}\text { Regression B : } \\
\text { Maternal Support }\end{array}$} \\
\hline & $\beta$ & $\mathrm{t}$ & $\beta$ & $\mathrm{t}$ \\
\hline $\begin{array}{l}\text { Emotional } \\
\text { Support }\end{array}$ & $.32 * *$ & 3.19 & -.18 & -1.78 \\
\hline $\begin{array}{l}\text { Esteem \& } \\
\text { Autonomy } \\
\text { Support }\end{array}$ & $-.23 * *$ & -2.82 & $.20 * *$ & 2.62 \\
\hline $\begin{array}{l}\text { Information } \\
\text { Provision }\end{array}$ & -.00 & -.01 & $.19 *$ & 2.20 \\
\hline $\begin{array}{l}\text { Tangible } \\
\text { Assistance }\end{array}$ & .13 & 1.73 & -.00 & -.05 \\
\hline$F$ & $7.52 * *$ & & $4.29 * *$ & \\
\hline $\mathrm{R}_{\text {Total }}^{2}$ & .09 & & .05 & \\
\hline $\mathrm{R}_{\text {Adjust }}^{2}$ & .07 & & .04 & \\
\hline
\end{tabular}

The results presented in Table II indicated that when comparing VEC, parental support effectively predicted children's TTF. Particularly, the father's emotional support, esteem and autonomy support, and mother's information provision and esteem and autonomy support significantly predicted their children's TTF. However, paternal esteem and autonomy support exhibited a negative predictive relationship. In other words, when fathers respect and support their children's autonomy, these children explored their vocations with an open-minded attitude during the vocational commitment process. Nonetheless, emotional support from fathers, and information provision, esteem and autonomy support from mothers allowed Taiwanese college students to achieve a high level of TTF, in which students narrow-mindedly believe that only one vocational option is appropriate for them and thus rendering them indifferent to exploring and identifying their vocational options.

\section{DISCUSSION}

Based on Super's model of career development, only complete vocational exploration contributes to mature vocational decisions. The model of identity formation by Marcia also indicates that exploration is crucial for making satisfactory vocational decisions and commitments to these decisions. Flum and Blustein [3] expressed an excellent interpretative opinion on this process, asserting that exploratory behavior facilitates interactions between the self and the world and thus can play an instrumental role in internalization. And a higher level of internalization enhances the experience of self-determination. Because of the importance of vocational exploration, numerous scholars have investigated whether parental support or relational support promotes children's vocational explorations. A few western empirical studies, as in [15], [16], confirmed that parental-care behavior toward children is significantly correlated with children's vocational exploration.

However, our results indicated that mother's information provision, esteem and autonomy support and paternal emotional support (but not esteem and autonomy support) adversely affected children's vocational exploration. This effect leads to student TTF on their vocational beliefs, inducing them to assume that only one vocational goal is suitable. This result is consistent with that obtained by Cheung and Arnold [17] who investigated the vocational explorations of college students in Hong Kong and showed that parental support was not significantly correlated with children's vocational explorations. Therefore, when examining the VEC of Chinese populations, researchers should consider the effects that the vocational expectation of traditional Chinese families have on their children. Because Chinese culture and community highly value family relationships and filial piety, children are encouraged to follow and fulfill parental expectations [18]. In other words, children must sacrifice their needs and suppress their autonomy to meet parental expectations. Typically, parental expectations conform to the values of mainstream society, in which parents long for their children to select high-paying jobs that involve high social status, rather than focusing on their children's interests in exploring and establishing life goals. Thus, research focusing on a Chinese population cannot achieve the positive result that parental support prompts children's VEC. This study found that only father's esteem and autonomy support was vital to children's VEC; however, the reason that the paternal rather than maternal influence was stronger requires further exploration.

\section{REFERENCES}

[1] D. L. Blustein, "A relational theory of working," Journal of Vocational Behavior, vol. 79, pp. 1-17, August 2011.

[2] D. E. P. Schultheiss, "A relational approach to career counseling: Theoretical integration and practical application," Journal of Counseling \& Development, vol. 81, no. 3, pp. 301-310, summer 2003. 
[3] H. Flum and D. L. Blustein, "Reinvigorating the study of vocational exploration: A framework for research," Journal of Vocational Behavior, vol. 56, pp. 380-404, June 2000.

[4] T. A. Fisher and M. B. Griggs, "Factors that influence the career development of African American and Latino Youth," The Journal of Vocational Education Research, vol. 20, no. 2, pp. 57-74, 1995.

[5] M. M. Nauta and M. L. Kokaly, "Assessing role model influences on students' academic and vocational decisions," Journal of Career Assessment, vol. 9, no. 1, pp. 81-99, Feb. 2001.

[6] M. Tang, N. A. Fouad, and P. L. Smith, "Asian Americans' career choices: A path model to examine factors influencing their caree choices," Journal of Vocational Behavior, vol. 54, no. 1, pp. 142-157, Feb. 1999.

[7] R. W. Lent, S. D. Brown, B. Brenner et al., "The role of contextual supports and barriers in the choice of math/science educational options: A test of social cognitive hypotheses," Journal of Counseling Psychology, vol. 48, no. 4, pp. 474-483, Oct. 2001.

[8] R. S. Sharf, Applying Career Development Theory to Counseling, 5th ed., Belmont, CA: Brooks/Cole, ch. 9, 2010.

[9] D. E. P. Schultheiss, H. M. Kress, A. J. Manzi, and J. M. J. Glasscock, "Relational influences in career development," The Counseling Psychologist, vol. 29, no. 2, pp. 214-239, March 2001.

[10] D. L. Blustein, L. D. Fama, S. F. White et al., "A Qualitative Analysis of Counseling Case Material," The Counseling Psychologist, vol. 29, no. 2, pp. 242-260, March 2001.

[11] S. D. Phillips, E. K. Christopher-Sisk, and K. L. Gravino, "Making career decisions in a relational context," The Counseling Psychologist, vol. 29, no. 2, pp. 193-213, March 2001.

[12] C. E. Cutrona, Social Support in Couples: Marriage as a Resource in Times of Stress, CA: Sage Publications, 1996, ch. 1.

[13] D. E. P. Schultheiss, T. V. Palma, K. S. Predragovich, and J. M. J. Glasscock, "Relational influences on career paths: Siblings in context," Journal of Counseling Psychology, vol. 49, no. 3, pp. 302-310, July 2002.

[14] D. L. Blustein, M. V. Ellis, and L. E. Devenis, "The development and validation of a two-dimensional model of the commitment to career choices process," Journal of Vocational Behavior, vol. 35, no. 3, pp. 342-378, Dec. 1989.

[15] B. Kracke, "Parental behaviors and adolescents' career exploration," The Career Development Quarterly, vol. 45, no. 4, pp. 341-350, June 1997.

[16] B. Kracke, "The role of personality, parents and peers in adolescents career exploration," Journal of Adolescence, vol. 25, no. 1, pp. 19-30, Feb. 2002.

[17] R. Cheung and J. Arnold, “Antecedents of career exploration among Hong Kong Chinese university students: Testing contextual and developmental variables," Journal of Vocational Behavior, vol. 76, no. 1, pp. 25-36, Feb. 2010.

[18] S. A. Leung, Z. J. Hou, I. Gati, and X. Li, "Effects of parental expectations and cultural-values orientation on career decision-making difficulties of Chinese University students," Journal of Vocational Behavior, vol. 78, no. 1, pp. 11-20, Feb. 2011.

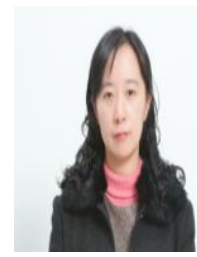

Ching-Hua Mao has got the master degree in Counseling Psychology at the Rutgers University (USA) in 1995. Currently, she is a PhD candidate of National Chiao-Tung University (Taiwan). Her research interest is in career counseling.

She is an assistant professor at the Chihlee Institute of Technology (Taiwan) since August 2001. She teaches courses of "Career Planning and Development", "Interpersonal Relationship and Communication", "Love and Gender", and "Business Managerial Psychology". 